\title{
Kanser Tanısı Olan Kişilerde Kabul ve Kararlılık Terapisi Uygulamaları: Sistematik Bir Derleme
}

\section{Acceptance and Commitment Therapy Interventions in Patients Diagnosed with Cancer: A Systematic Review}

\author{
Samet Baş ${ }^{1}$ [D, Gülay Dirik² ()
}

'Arş. Gör., Dokuz Eylül Üniversitesi, Edebiyat Fakültesi, Psikoloji Bölümü, İzmir, Türkiye ${ }^{2}$ Prof. Dr., Dokuz Eylül Üniversitesi, Edebiyat Fakültesi, Psikoloji Bölümü, İzmir, Türkiye

ORCID: S.B. 0000-0002-5518-7576; G.D. $0000-0002-5748-9180$

\section{Sorumlu yazar/Corresponding author:} Samet Baş,

Dokuz Eylül Üniversitesi, Edebiyat Fakültesi, Psikoloji Bölümü, Adatepe Mah. Doğuş Cad. No: 207/M 35390, Tınaztepe Yerleşkesi, Buca, İzmir, Türkiye

E-posta/E-mail: sametbas@yahoo.com

Başvuru/Submitted: 14.03.2019 Revizyon Talebi/Revision Requested: 19.03.2019

Son Revizyon/Last Revision Received: 07.08.2019

Kabul/Accepted: 12.08 .2019

Online Yayın/Published Online: 13.12.2019

Atıf/Citation: Bas, S., Dirik, G. (2019). Kanser tanısı olan kişilerde kabul ve kararlılık terapisi uygulamaları: Sistematik bir derleme. Psikoloji Çalışmaları - Studies in Psychology, 39(2): 459-485.

https://doi.org/10.26650/SP2019-0025

\section{öz}

Kanser, bu hastalığa sahip olan kişilerin fiziksel sağlık durumları üzerindeki olumsuz etkilerin yanı sıra önemli psikolojik sorunları da beraberinde getiren ciddi bir hastalıktır. Günümüzde psikolojik tedaviler olumsuz belirtilerin azaltılmasında etkili sonuçlar ortaya koymaktadır. Üçüncü kuşak bilişsel davranışçı psikoterapilerden biri olan Kabul ve Kararlılık Terapisi kanser hastalarında belirtilerin azaltılmasında önemli bir tedavi yaklaşımıdır. Özellikle hastalığın kendisinin ve olumsuz etkilerinin kabul edildiği ve psikolojik esneklik düzeyinin yüksek olduğu durumlar daha az belirti ve hastalık sürecine uyum gösterme davranışında artış gibi olumlu sonuçlarla ilişkili bulunmaktadır. Bu çalışma kapsamında kanser hastalarının psikolojik sorunlarına yönelik uygulanmış Kabul ve Kararlılık Terapisi temelli tedavi yaklaşımları sistematik bir şekilde değerlendirilmiştir. Sadece kanser hastaları örneklemini, en az ön test ve son test ölçümleri ve Kabul ve Kararlılık Terapisinin temel bileşenlerini kapsayan bir müdahaleyi kullanmak gibi içleme kriterlerini karşılayan on beş çalışma detaylı olarak incelenmiştir. Sonuçlar, uygulanan tedaviler sonrasında hem tedavi öncesine hem de kontrol gruplarına kıyasla kanser hastalarının psikolojik esneklik, travma sonrası gelişim, maneviyat ve yaşam kalitesi düzeylerinde anlamlı artışlar olduğunu; hastalığın tekrar edeceği korkusu, depresyon, kaygı, stres, duygusal kontrol ve düşünceleri bastırma davranışlarında ise anlamlı azalmalar olduğunu göstermektedir. Ayrıca, sadece tedavi öncesine göre farkındalık düzeylerinde artış gözlenirken, ağnı ve ilişkili belirtiler, tükenmişlik, uyku sorunları ve hareketsiz yaşam tarzında anlamlı azalmalar görülmüştür. Hem bireysel hem de grup olarak nispeten kısa süreli bir şekilde uygulanabilen Kabul ve Kararlılık Terapisi temelli müdahale yöntemleriyle kanser hastalarının olumsuz psikolojik belirtileri azaltılabilir ve bunun yanında yaşama dair beklentilerinin ve yaşam kalitelerinin artması sağlanabilir. Ancak müdahalenin güvenirliğinin artması ve farklı kanser hastalarına genellenebilmesi için gelecekte yöntemsel açıdan daha kontrollü ve terapi kazanımlarının daha uzun dönemli olarak takip edileceği çalışmalara ihtiyaç duyulmaktadır.

Anahtar Kelimeler: Kanser, kabul ve kararlılık terapisi, psikolojik esneklik, sistematik derleme 


\section{ABSTRACT}

Cancer is a serious disease that brings with it important psychological problems as well as the negative effects on the physical health of survivors. Nowadays, psychological treatments reveal effective results on reducing such negative symptoms. Acceptance and Commitment Therapy (ACT) - one of the third wave behavioral and cognitive psychotherapies - is an important treatment approach in reducing the negative symptoms of cancer survivors. In particular, situations in which the disease itself and its adverse effects were accepted and the level of psychological flexibility was high were found to be associated with less negative symptoms and more positive outcomes such as adherence with the disease process. This study systemtically evaluated ACT based interventions on the psychological problems of cancer survivors. Fifteen studies that met the following criteria were examined in detail: using only a sample of cancer patients, having at least a pre-test and a post-test assessment, and an intervention involving basic components of ACT. The results showed that following the treatments, there were significant increases in psychological flexibility, posttraumatic growth, spirituality, quality of life and significant decreases in fear of recurrence, depression, anxiety, stress, emotional control, and thought suppression levels of patients when comparing both pre-treatment and control groups. Additionally, there were significant increases in mindfulness compared to pre-treatment results alone, but a significant decrease in pain and related symptoms, burnout, sleep problems and sedentary behaviors. ACT interventions, which can be applied both individually or in groups and over relatively short period of time, are promising as an alternative treatment for cancer patients to reduce their negative psychological symptoms as well as to increase their life expectancy and quality of life. However, in order to generalize the findings for different cancer patients and to increase the confidence of intervention, future studies should be more controlled, reliable and long-term.

Keywords: Cancer, acceptance and commitment therapy, psychological flexibility, systematic review

\section{EXTENDED ABSTRACT}

Studies indicate that cancer causes a negative effect on both the physical and psychological health status of patients. Meta-analysis and review studies demonstrate that psychological therapies show promising effects on reducing the stress levels of cancer survivors and increasing their quality of life (De la Torre-Luque, Gambara, López \& Cruzado, 2015; Linden \& Girgis, 2012). The concept of acceptance has an important role in the course of the cancer disease. This concept includes acceptance of both the disease itself and the altered body image after treatment (e.g., as common in breast cancer patients). Research indicates that acceptance of the cancer disease increases the commitment to cancer and treatment process (Kamińska et al., 2014). Although Acceptance and Commitment Therapy (ACT) interventions are quite limited, they are promising as an important alternative treatment in reducing the symptoms of cancer survivors (Fashler, Weinrib, Azam ve Katz, 2018). More detailed studies such as systematic reviews or meta-analyses are needed to examine the existing studies in terms of methodological issues and study results. For this reason, a systematic review was carried out in examining the current status of ACT-based treatment studies in the context of cancer patients. 


\section{Method}

The EBSCOhost, Web of Science, PubMed, Science Direct and Google Scholar, ULAKBIM, and TR Dizin databases were used to search examples of literature which included studies up to August 2018. The keywords "cancer" and "acceptance and commitment therapy" or "ACT" were used for studies in English and Turkish languages. A total of 205 studies were identified with this search, and then repeated articles were excluded. Following the title and summary review, articles which did not meet the inclusion criteria were excluded. The full text of the remaining 15 studies were examined in detail.

\section{Results}

In total, 1200 people with different types of cancer (mainly breast cancer), were included and various ACT based interventions were implemented through the remaining 15 studies. Almost two thirds of the participants were female $(N=745 ; 62 \%)$ and mainly adults between the ages 12-75 $(M=49.8)$. The findings were gathered according to their common goals such as psychological flexibility, psychological symptoms and fear of recurrence etc.

Eight of the nine studies (89\%) measuring psychological flexibility showed significant increases within the group compared to the pre-test and post-test and the gains were maintained for up to 12 months. In all four studies - including the control group - significant differences were observed between the groups and the gains of the treatment group were maintained for up to six months.

In eight studies measuring depression (89\%), within group differences decreased significantly after ACT treatment and gains remained for up to three months. In addition, in four of the five studies (80\%) using the control group, the differences between the groups decreased significantly for depression. The gains were maintained for up to three months after treatment. In seven of the eight studies (88\%) measuring anxiety levels, significant differences were found within the group, while the gains were maintained in the three-month follow-up assessment. In the control group comparisons, in three of the five studies (60\%), the differences between the groups significantly decreased in terms of anxiety level. The gains were maintained in follow up assessments up to three months later. For stress, significant improvements were observed within the group in four studies, while the gains were maintained for up to 12 months. However, in the comparison of the control group, differences between the groups were significant only in one study. These gains continued for up to three months.

Significant improvements were found in quality of life and related variables in all eight studies following the ACT treatment. In addition, treatment gains were maintained for up to 
12 months. In terms of group differences, in three studies using no-treatment and treatment as the usual control conditions, significant differences were found between the groups in post-test and follow-up assessments for up to six months. Only in the study with normal care control groups, was there no significant difference between the groups in quality of life. In addition to these factors, studies showed that there were significant improvements in posttraumatic growth, spirituality, recurrence anxiety, emotional control and suppression of thoughts compared to both pre-treatment and control groups. Moreover, significant improvements were observed in mindfulness, pain and related symptoms, burnout, sleep problems, and sedentary behaviors compared to the only pre-treatment group. All the gains were maintained after the interventions for an average of 4.1 months for within groups and 5 months on a between-groups basis.

\section{Discussion}

As a result, ACT based intervention methods show effective results in reducing the psychological problems of survivors with different types of cancer as a new treatment approach. Although the results show that ACT is an effective treatment for many symptoms of cancer survivors, more controlled, randomized and long-term studies are needed. 
Kanser hem dünyada hem de ülkemizde başlıca ölüm nedenlerinden biri olarak karş1mıza çıkan önemli kronik bir hastalıktır. Dünya Sağlık Örgütünün (DSÖ) yayınlamış olduğu dünya genelindeki başlıca on ölüm nedeni arasında altıncı sırada kanser gelirken (DSÖ, 2018), ülkemizde iyi ve kötü huylu tümörler ölüm nedenleri arasında \%20’lik bir oranla ikinci sırada yer almaktadır (Türkiye İstatistik Kurumu, 2018). Ülkemizde erkekler için en yaygın kanser türleri trakea, bronş-akciğer (\%21) ve prostat (\%13); kadınlarda meme (\%25) ve tiroid (\%12); çocuklarda ise lösemi (\%37), merkezi sinir sistemi tümörleri (\%18) ve lenf kanseri (lenfoma) (\%16) şeklinde sıralanmaktadır (Şencan ve Keskinkılıç, 2017).

Yapılan çalışmalar kronik hastalıklardan biri olan kanserin, hastaların fiziksel sağlıklarının yanı sıra psikolojik sağlıklarını da olumsuz yönde etkilediğine işaret etmektedir. Farklı tür kanser tanısı olan kişilerde karın ağrıları, yorgunluk, uyku sorunları (Heins, Korevaar, Rijken ve Schellevis, 2013), cinsel yaşam sorunları (Yaman ve Ayaz, 2016), engellenme, umutsuzluk, öfke kontrolünde zorluk, beden imgesinde bozulmalar, uyum bozuklukları, depresif bozukluklar ve kaygı bozuklukları (Gregurek, Bras, Dordević, Ratković ve Brajković, 2010; Miovic ve Block, 2007) yaygın olarak görülen sorunlardır.

Kanser hastalıklarında yukarıda bahsedilen sorunlardan yola çıkılarak psikolojik faktörlerin önemli bir rolü olduğu düşünülebilir. Bu faktörlerin hastalığın başlangıcı açısından sağlık ve hastalık inançları, sağlık davranışları ve davranış değişikliği müdahalelerinin yanı sıra tanı ve tedavi açısından tarama, yardım arama davranışı, tedavide gecikme ve tedavi uyumu, baş etme, ve yaşam kalitesini etkileyen konularda önemli etkenler olduğu belirtilmektedir (Ogden, 2016). Konuyla ilgili meta-analiz ve derleme çalışmaları psikolojik tedavilerin kanser tanısı olan kişilerin stres düzeylerinin azaltılması ve yaşam kalitelerinin arttırılması açısından önemli bir etkiye sahip olduğuna işaret etmektedir (De la Torre-Luque, Gambara, López ve Cruzado, 2015; Linden ve Girgis, 2012).

Kanser tanısı olan kişilere uygulanan psikolojik müdahaleler incelendiğinde öz yönetim stratejileri (Dunne ve ark., 2017), telefon/internet temelli müdahaleler (Ream, Gargaro, Barsevick ve Richardson, 2015; Wootten ve ark., 2016), motivasyonel görüşme teknikleri (Spencer ve Wheeler, 2016), bilişsel davranışçı terapi (BDT), farkındalık temelli müdahale programları (Johns ve ark., 2016; Yastıbaş ve Dirik, 2018), Kabul ve Kararl111k Terapisi (Acceptance and Commitment Therapy: ACT) ${ }^{1}$ (Hulbert-Williams,

1 Acceptance and Commitment Therapy’nin kısaltması ve Türkçe karşılığı "eylem/hareket” olan ACT kelimesi, tedavideki değerler doğrultusunda hareket etmeyi vurguladığından, başka dillerde de "ACT” şeklinde kısaltılması önerilmektedir (Harris, 2016). Ulusal ve uluslararası yayınlardaki tutarlılığı devam ettirmek amacıyla bu çalışma kapsamında Türkçe kısaltması KKT şeklinde değil ACT olarak kullanılmıştır. 
Storey ve Wilson, 2015) gibi tedavi yöntemlerinin kullanıldığı görülmektedir. Bu müdahale yöntemleri arasında her ne kadar BDT araştırmacılar ve uygulamacılar tarafından sıklıkla tercih edilen bir yöntem olsa da son zamanlarda üçüncü kuşak psikoterapilerden biri olarak gösterilen ACT’nin kanser hastalığı ile ilişkili psikolojik sorunların tedavisinde kullanımındaki artış dikkat çekmektedir.

Bu çalışmanın amacı, kanser hastalarında yukarıda belirtilen psikolojik sorunların azaltılmasına yönelik uygulanan ve günümüzde sayıları gittikçe artan ACT temelli müdahale çalışmalarına yönelik bir sistematik alan derlemesi gerçekleştirmektir. Bilindiği kadarıyla, son yıllarda gerçekleştirilen en güncel tedavi çalışmalarına ait sonuçların detaylı ve açık bir şekilde değerlendirildiği sistematik bir alan derleme çalışması henüz bulunmamaktadır. $\mathrm{Bu}$ çalışma ile ACT açısından oldukça sınırlı olan özellikle Türkçe alan yazına önemli bir kaynak sunulmuş olacaktır. Bunun için öncelikle hem ACT hem de kanserde en yaygın kullanılan tedavi yaklaşımı BDT'ye yönelik geçmiş alan yazın bilgisine yer verilecektir.

\section{Kanser ve Bilişsel Davranışçı Terapi}

Yapılan derleme çalışmaları BDT'nin farklı tür kanser tanısı olan hastaların sorunlarının azaltılmasında hem bireysel hem de grup olarak etkili bir tedavi yöntemi olduğuna işaret etmektedir (Faraji, Mahdavi, Samkhaniyan, Asadi ve Dezhkam, 2015; Xiao ve ark., 2016). Kanser hastalarına yönelik gerçekleştirilen BDT uygulamalarında genel olarak bilişsel yeniden yapılandırma, imgesel ya da yaşantısal (in-vivo) maruz bırakmalar, başa çıkma becerileri eğitimi, problem çözme, davranışsal deneyler, ev ödevleri, kabul ve farkındalık temelli teknikler kullanılmaktadır (Nenova ve ark., 2013).

Xiao ve arkadaşları (2016) tarafından gerçekleştirilen meta-analiz çalışmasında, meme kanseri ameliyatı sonrası hastaların depresyonlarına yönelik gerçekleştirilmiş psikolojik müdahalelerin sonuçları değerlendirilmiştir. Bulgular bireysel BDT uygulamasının depresyonun azaltılmasında önemli bir etkiye sahip olduğunu göstermektedir. Meme kanseri olan kadınlarla yapılan çalışmalar, BDT grup müdahalesinin de hastaların depresyon, kaygı ve Travma Sonrası Stres Bozukluğu belirtilerinin yanı sıra beden imgesine yönelik endişelerin azaltılmasında etkili olduğuna işaret etmektedir (Faraji ve ark., 2015). Peoples ve arkadaşları (2017) tarafından gerçekleştirilen randomize plasebo kontrollü bir çalışmada insomnia sorunu ve kanser tanısı olan 95 hastaya, bireysel BDT uygulanmıştır. Tedavi sonrasında ve üç aylık takip çalışmasında insomniada azalmalar ve yaşam kalitelerinde ilerlemeler kaydedilmiştir. Yakın zamanda gerçekleştirilen 
bir başka araştırmada sekiz seanslık telefon destekli bireysel BDT'nin yüz yüze BDT uygulaması ile kıyaslaması gerçekleştirilmiştir. Bulgulara göre kaygı, depresyon ve kansere yönelik endişe düzeyleri açısından her iki tedavi grubunda da anlamlı azalmalar gerçekleşmiştir (Watson, White, Lynch ve Mohammed 2017).

\section{Kanser ile Kabul ve Kararlılık Terapisi}

Kanser tanısı olan kişilere yönelik psikoloji alan yazındaki tedavi çalışmaları incelendiğinde kabul kavramının hastalığın gidişatı açısından önemli bir yere sahip olduğu görülmektedir. Bu kavram hem hastalığın kendisinin hem de tedavi sonrası değişen beden imgesinin kabul edilmesini içermektedir. Araştırmalar kanser hastalığına yönelik kabul düzeyleri arttıkça tedaviye yönelik uyumların da artış gösterdiğine işaret etmektedir (Kamińska ve ark., 2014). Beden imgesine yönelik kabul sürecinin ise aşamalı, karmaşık ve devamlı bir süreç olduğu nicel çalışmalar vasıtasıyla gösterilmiştir (Buki, Reich ve Lehardy, 2016). Kanser hastası bireylerin yaşı ilerledikçe duygusal kabul düzeyleri (Politi, Enright ve Weihs, 2007), tanı alınan süre ilerledikçe de öz kabul düzeyleri artış göstermektedir (Chen, Liu, Zhang ve Li, 2017).

ACT, üçüncü kuşak bilişsel davranışçı bir psikoterapi yaklaşımı olarak kabul edilmektedir (Hayes, 2004). Olumsuz duygu ve düşünceleri deneyimlemek ve yönetmek konusunda insanları teşvik eden bir tedavi yaklaşımıdır ve temel amacı psikolojik esnekliği arttırmaktır. Bu bağlamda ACT tedavi modeli psikolojik esnekliği temsil eden altı temel bileşen içermektedir. Bunlar anda olmak, değerler, kabul, ayrışma (diffusion), bağlamsal benlik ve değerler doğrultusunda davranışlar şeklindedir (Hayes, Strosahl ve Wilson, 1999). Anda olmak içinde bulunulan psikolojik ve çevresel durumlara eleştirel olmadan gönüllü ve esnek bir biçimde odaklanma halidir. Değerler ise kişilerin kendisinin belirlediği ve değişkenlik gösterebilen kariyer, aile gibi uzun vadeli yaşamsal hedefleri temsil etmektedir. Bu yönüyle değerler, ACT müdahalelerinin temel amacıdır. Kabul kavramı ise pasif bir şekilde boyun eğme davranışından farklı olarak, kişisel yaşama dair durumların etkin ve açık bir şekilde, onları değiştirmeye çabalamadan sahiplenilmesi halidir (örn., kaçınmalar olmadan kaygının bir duygu olarak tamamen hissedilmesi gibi). Düşüncelerin davranışlar üzerindeki baskınlığı sonucunda kişinin içinde bulunduğu ortama uygun davranışlar sergileyememesi bilişsel birleşme olarak adlandırılır. Buna karşılık bilişsel ayrışma teknikleri sayesinde ise bu düşüncelerin davranış üzerindeki istenmeyen etkisi değiştirilmeye çalışılır. Düşüncenin sıklığı ya da şekline müdahale edilmez. Bağlamsal benlik kavramıyla kişinin deneyimlediği yaşantılarına yönelik perspek- 
tif alabilme durumuna atıfta bulunulur. Yaşanan deneyimlerde "diğerleri” yerine "ben"e, bir başka zaman/mekan yerine "şimdi/burada"ya temas etmek esastır. Bu sayede kişi kendi deneyimlerine bağlı kalmadan ve onlar tarafından kuşatılmadan yaşadıklarının farkındadır. Son olarak, ACT kişinin belirlediği yaşam değerleri doğrultusunda etkili davranış eğilimlerinin gelişimini önemseyen bir yaklaşımdır. Bu doğrultuda maruz bırakma, beceri edinimi ve hedef belirleme gibi birçok davranışçı teknik ACT protokolü içerisinde yer almaktadır (Hayes, Luoma, Bond, Masuda ve Lillis, 2006; Yavuz, 2015).

Diğer geleneksel bilişsel davranışçı tedavi yaklaşımlarından farklı olarak ACT için temel hedef psikolojik belirtilerin azaltılması değil, kişinin belirtilerle olan ilişkisini değiştirerek ana odaklı değerler doğrultusunda bir yaşama ulaşmasını sağlamaktır (Harris, 2016). Bu bağlamda yukarıda bileşenleri açıklanan psikolojik esneklik kavramı, değerlerimize açıklıkla ve dikkatli bir şekilde yaklaşarak anda bulunmak ve değerlerimiz doğrultusunda yaşamak olarak özetlenebilir ve araştırmalarda yaygınlıkla Kabul ve Eylem Ölçeği-II (Acceptance and Action Questionnaire-II [AAQ-II], Bond ve ark., 2011) aracılığıyla değerlendirilmektedir. Farklı tür kanser tanısı olan kişilerde psikolojik esnekliğin kayg1, depresyon, olumsuz duygu durum ve yaşam kalitesi ile ilişkili olduğu belirtilmektedir (Hulbert-Williams ve ark., 2015). ACT, Amerikan Psikoloji Derneği Klinik Psikoloji Topluluğu (Division 12) ${ }^{2}$ tarafından sıralanan günümüz kanıt temelli tedavileri arasında yerini almaktadır ve kronik ağrı (Veehof, Oskam, Schreurs ve Bohlmeijer, 2011), depresyon (Forman ve ark., 2012), kaygı bozuklukları, obsesif kompulsif ve ilişkili bozukluklar (Bluett, Homan, Morrison, Levin ve Twohig, 2014; Swain, Hancock, Hainsworth ve Bowman, 2013) ve psikoz (Bach, Hayes ve Gallop, 2012) gibi bozukluklar için etkinliği gösterilmiş bir tedavi yaklaşımıdır.

Graham, Gouick, Krahé ve Gillanders (2016) tarafından gerçekleştirilmiş bir sistematik derleme çalışmasında, kronik hastalıklar ve uzun dönemli sorunlarda ACT uygulamaları ele alınmıştır. Derlemeye dahil edilen çalışmalarda randomize kontrollü desenle ele alınan müdahale araştırmaları ve vaka çalışması desenleri kullanılmıştır. Ele alınan araştırmalarda, yaşam kalitesi ve stresin azaltılması gibi birçok uygulama gerçekleştirilmiş ve AIDS, epilepsi, kanser gibi çeşitli hastalıklar ele alınmıştır. Sonuçlar her ne kadar psikolojik esneklik ve öz yönetim gibi alanlarda ilerlemelerin kaydedildiğini göstermiş olsa da, ACT araştırmalarının yöntemsel konular ve müdahale kaliteleri açı-

2 https://www.div12.org/psychological-treatments/treatments/ 
sindan yetersiz olduğuna ve bu nedenle kronik bozukluklar ve uzun dönemli sorunlar için henüz iyi yapılandırılmış çalışmalar olmadığına işaret etmektedir. Öte yandan söz konusu derleme, kanser hastalığının yanı sıra AIDS ve epilepsi gibi diğer hastalıkları da kapsamakta ve yöntemsel olarak sadece randomize kontrollü çalışmaları değil, vaka çalışmalarını da içermektedir.

Sonuç olarak alan yazında kanser hastalığı olan bireylere yönelik ACT temelli müdahaleler incelendiğinde yapılan çalışmaların sınırlı olduğu görülmektedir. Var olan çalışmaların yöntemsel hususlar ve çalışma sonuçları açısından daha detaylı incelenebilmesi içinse sistematik derleme ya da meta-analiz gibi daha kapsamlı çalışmalara ihtiyaç duyulmaktadır (Örn., Fashler ve ark., 2018). Kanser hastalarında psikolojik faktörlerin öneminden hareketle üçüncü kuşak bilişsel davranış̧̧ı müdahale yaklaşımı olan ACT'nin, kanser tanısı olan kişilerin psikolojik tedavi ihtiyacına önemli bir katkı sunacağı düşünülmektedir. Bu nedenle şimdiki çalışma kapsamında, alan yazında var olan ACT temelli tedavi çalışmaların daha detaylı olarak incelenebilmesi amacıyla sistematik bir derleme çalışması yürütülmüştür. Bu sayede gerçekleştirilmiş tedavi çalışmalarının kanser hastaları açısından ne gibi sonuçlar ortaya koyduğu daha net biçimde görülebilecektir.

\section{YÖNTEM}

\section{Tarama ve Seçim Süreci}

Yapılan çalışmada sistematik derlemelerin ve meta-analizlerin yazımında kanıta dayalı ölçütleri esas alan PRISMA akış şeması kullanılmıştır (Liberati ve ark., 2009). EBSCOhost, Web of Science, PubMed, Science Direct ve Google Scholar, ULAKBIM, TR Dizin veri tabanları kullanılarak Ağustos 2018 ve öncesi çalışmaları içeren bir alan yazın taraması yapılmıştır. Tarama yapılırken İngilizce ve Türkçe dillerindeki çalışmalar için "cancer", "kanser", "acceptance and commitment therapy" ve "kabul ve kararlılık terapisi" ya da "ACT" anahtar kelimeleri kullanılmıştır.

Derleme kapsamına alınma ölçütleri, çalışmaların 2018 ve öncesinde gerçekleştirilmiş olması, örneklemi sadece kanser hastalarından oluşması, en az bir ön test ve son test ölçümü içermesi ve ACT'nin temel bileşenlerini kapsayan bir müdahaleyi içermesi olarak belirlenmiştir. Çalışmada, kanser hastalı̆̆ının türü açısından herhangi bir sınırlandırma kriteri getirilmemiştir. Dışlama kriterleri olarak ise derleme çalışmalar, yayınlanmamış tez çalışmaları, konferans bildiri özetleri, nitel araştırmalar, tedavi planları, kanserin yanı sıra başka kronik hastalıklara sahip örneklem içeren çalışmalar, kanser hastalarının 
yakınları ile gerçekleştirilen ve kısmen bir ACT tedavisi uygulanan araştırmalar belirlenmiştir. Ek olarak, tam metin ulaşılamayan ve İngilizce ya da Türkçe dillerinde olmayan araştırmalar da derleme kapsamı dışında tutulmuştur.

Tarama sonucunda toplam 205 adet çalışmaya ulaşılmıştır (Web of Science: 103, EBSCOhost: 58, PubMed: 17, ULAKBIM: 16, Science Direct: 7, TR Dizin: 2 ve diğer kaynaklar: 2). Diğer kaynaklar kısmında veri tabanlarınca tespit edilmeyen ancak tarama yapılırken derleme çalışmalar içerisinde tespit edilen iki araştırma yer almaktadır. Şekil 1'de gösterildiği gibi tekrar eden çalışmalar çıkarıldıktan sonra kalan 118 araştırma, başlık ve özet bilgileri doğrultusunda incelenmiş ve yukarıda sıralanan dışlama kriterlerine takılan, İngilizce veya Türkçe dışındaki dillerce yazılmış olan 80 çalışma çıka-
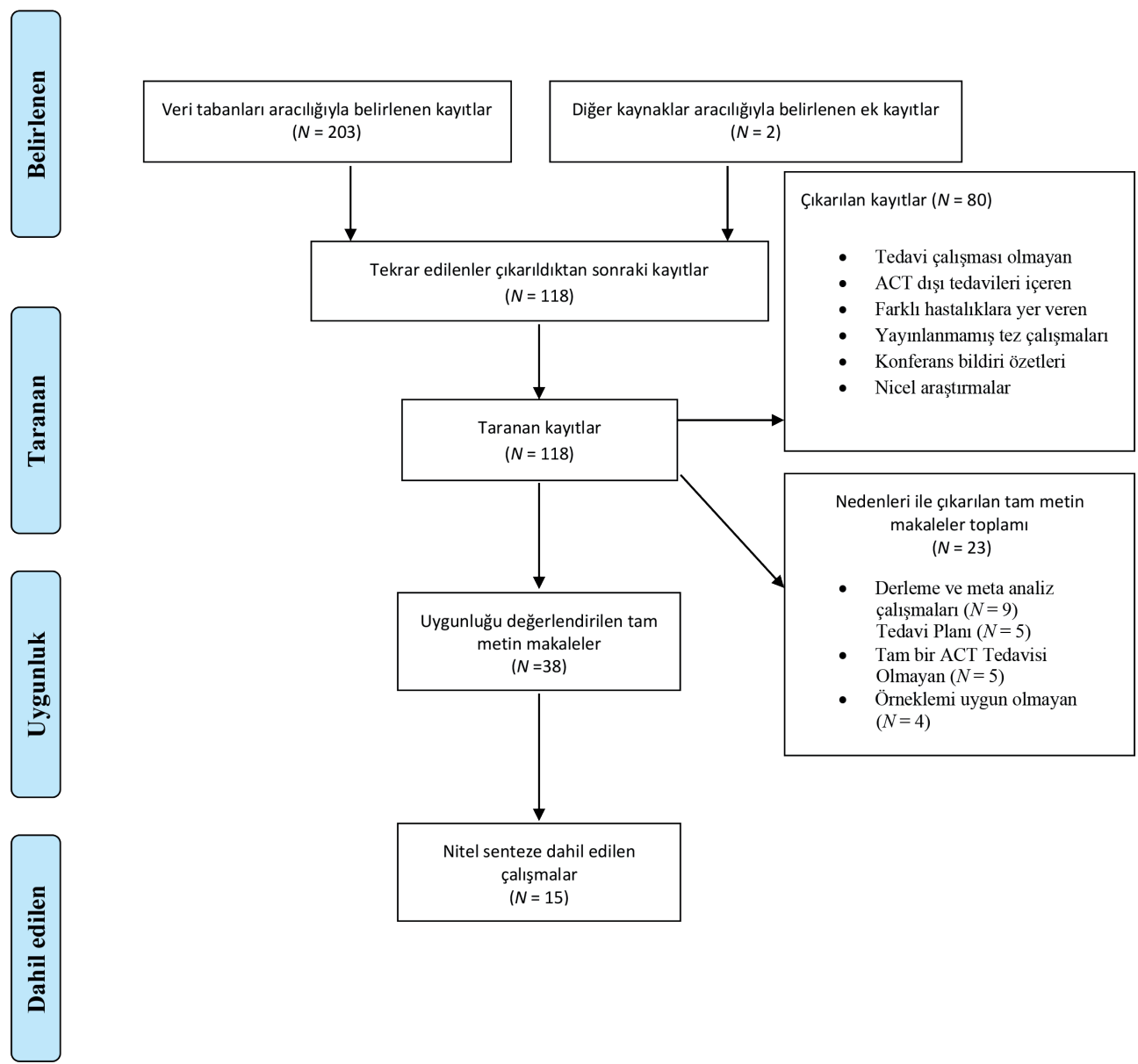

Şekil I. PRISMA Akış Şeması 
rılmıştır. Geriye kalan ve detaylı olarak incelenen 38 tam metin makaleden derleme çalışmalar, tedavi planı sunan araştırmalar, kısmen bir ACT tedavisi uygulamış olanlar ve örneklem açısından uygun olmayanlar (örn., kanser hastalarının yakınlarıyla gerçekleştirilen çalışmalar) çıkarıldıktan sonra geriye en az ön test ve son test araştırma deseni kullanan toplam 15 çalışma kalmıştır. Bu çalışmalar, pek çok farklı açıdan detaylı olarak değerlendirmeye alınmıştır.

\section{BULGULAR}

Yapılan tarama sonrasında elde edilen çalışmalardan yukarıda belirtildiği üzere dışlama kriterleri doğrultusunda bazıları çıkarılmış ve son olarak değerlendirme 15 araştırma üzerinden gerçekleştirilmiştir. Bu doğrultuda çalışmalar Tablo 1'de gösterilen başlıklar ekseninde değerlendirilmiştir.

\section{Çalışmaların Desenleri}

Değerlendirilen 15 çalışmanın tamamında ön ve son test ölçümlerin alındığg araştırma desenleri kullanılmıştır. Bunlardan 10 tanesinde en az bir kontrol grubu kullanılmıştır (\%67). Çalışmaların dört tanesinde (\%26.7) randomize kontrollü araştırmalar gerçekleştirilmiştir (Bkz. Tablo 1). Detaylı olarak incelendiğinde Arch ve Mitchell'in (2016) çalışmasında tek grup çoklu temel ölçümler, Kangas, McDonald, Williams ve Smee'nin (2015) çalışmasında ise vaka serileri deseni kullanılmıştır. Kalan çalışmaların altısında (\%40) ön ve son test kontrol gruplu araştırma deseni kullanılırken (Ghasemi, Dehghan, Farnia, Tatari ve Alikhani, 2016; Mohabbat-Bahar, Maleki-Rizi, Akbari ve Moradi-Joo, 2015; Montazer, Nemati, Dehghani ve Fallah, 2017; Montesinos ve Luciano, 2016; Najvani, Neshatdoost, Abedi ve Mokarian, 2015; Rost, Wilson, Buchanan, Hildebrandt ve Mutch, 2012), diğer üç araştırmada (\%20) tek grup ön ve son test desen kullanılmıştır (Datta, Aditya, Chakraborty, Das ve Mukhopadhyay, 2016; Feros, Lane, Ciarrochi ve Blackledge, 2013; Martin ve ark., 2016).

Araştırmaların sekizinde (\%53) 1-12 ay (Ort. = 5 ay) aralığında değişen takip ölçümleri alınmıştır. En uzun süreli takip değerlendirmesi Hawkes, Pakenham, Chambers, Patrao ve Courneya (2014) ve Lynch, Courneya, Sethi, Patrao ve Hawkes (2014) tarafından 12 ay süreli olarak gerçekleştirilmiştir. Bunun yanı sıra üç çalışmanın son test ölçümleri 1-3 ay zaman aralığında değişen periyotlarda alınmıştır (Datta ve ark., 2016; Martin ve ark., 2016; Rost ve ark; 2012). 


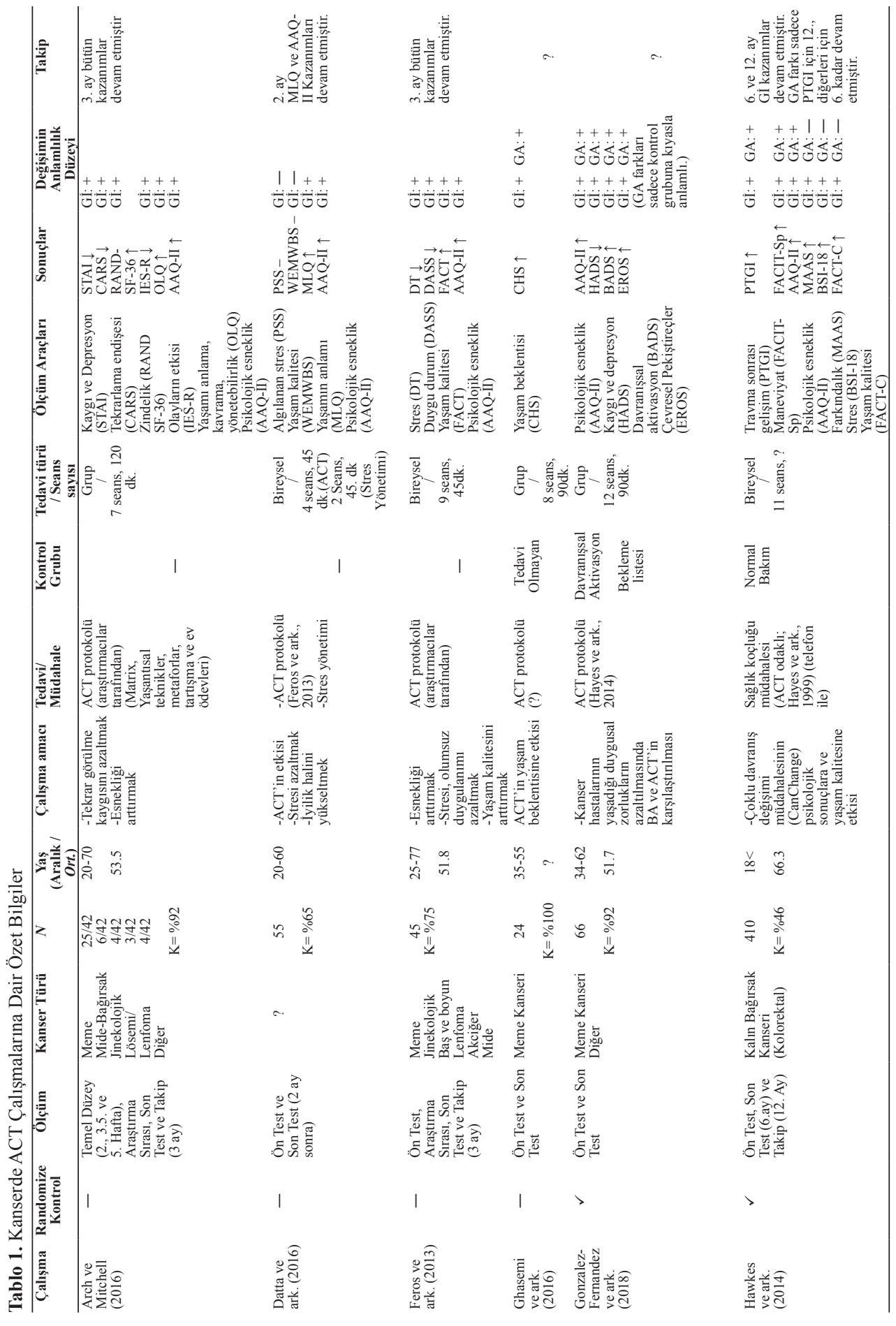




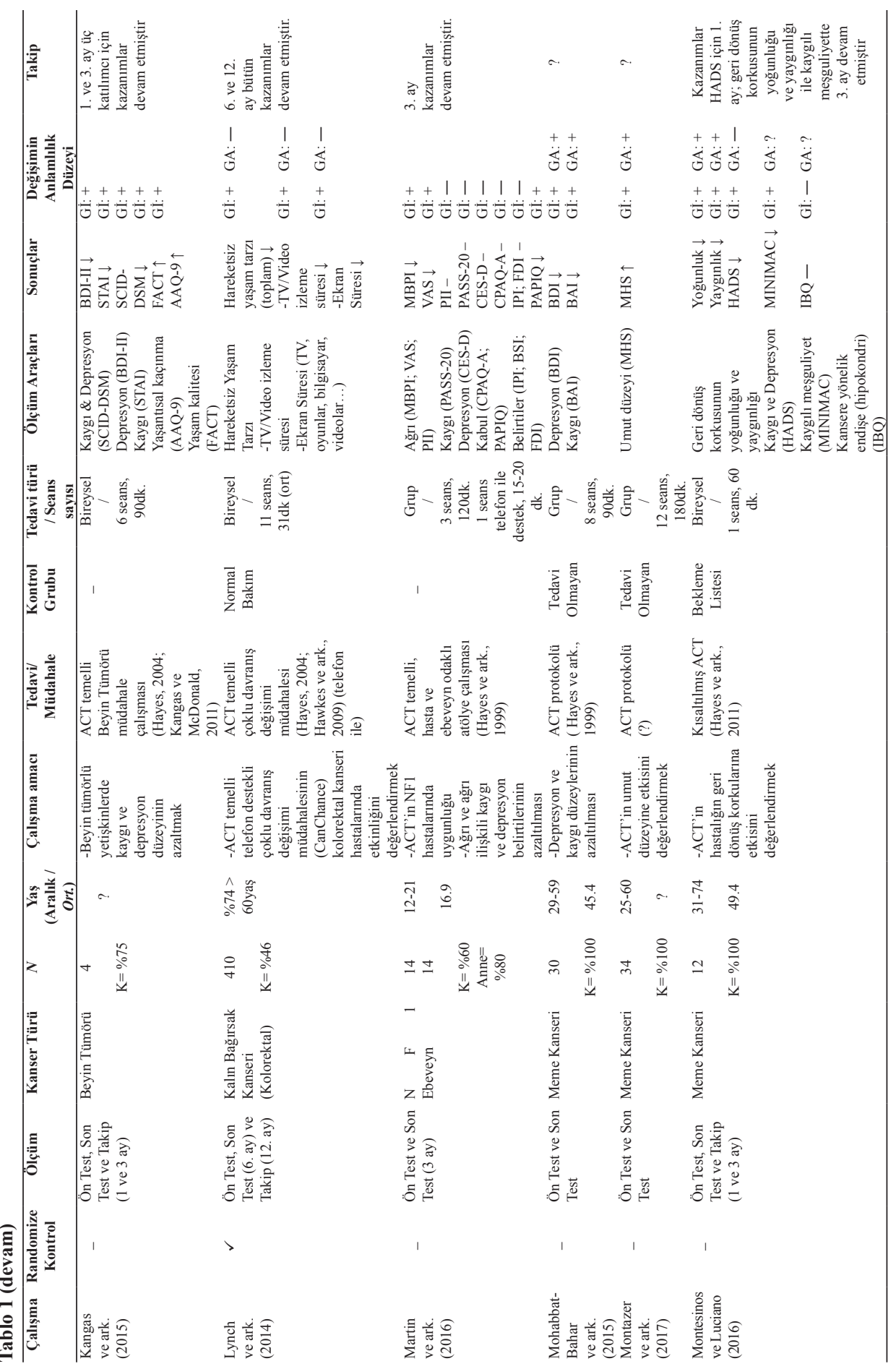




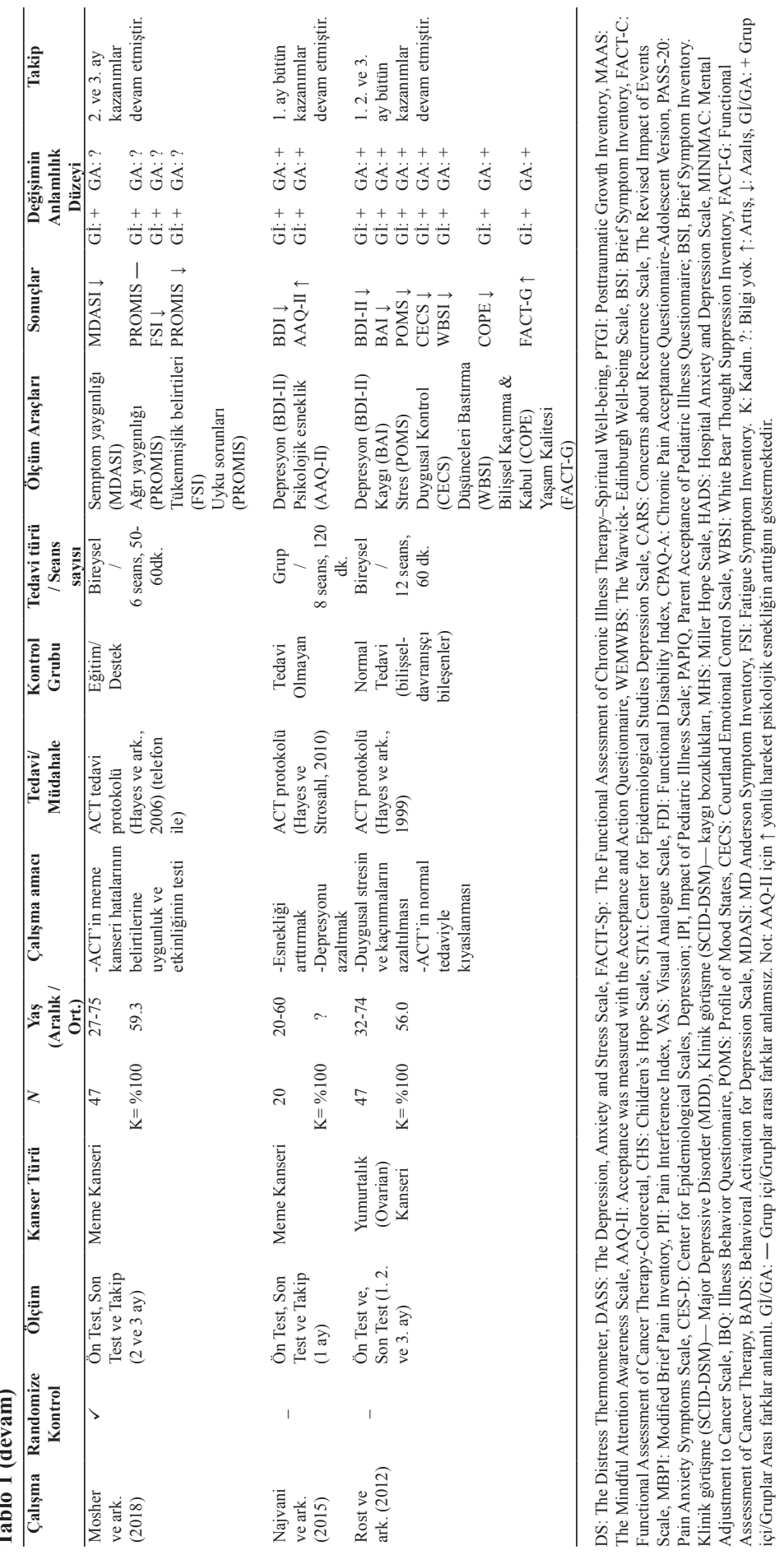




\section{Örneklem Özellikleri}

Çalışmaların örneklem özellikleri incelendiğinde yedi araştırmada (\%47) sadece meme kanseri tanısı olan kişilerin araştırmaya dahil edildiği görülmektedir (Ghasemi ve ark., 2016; Gonzalez-Fernandez, Fernandez-Rodriguez, Paz-Caballero ve Perez-Alvarez, 2018; Mohabbat-Bahar ve ark., 2015; Montazer ve ark., 2017; Montesinos ve Luciano, 2016; Mosher ve ark., 2018; Najvani ve ark., 2015). İki araştırmada ise birden çok kanser türü olan kişiler (örn., meme, mide-bağırsak, jinekolojik, lösemi, lenfoma, baş ve boyun ve akciğer gibi) örneklemde yer almıştır (Arch ve Mitchell, 2016; Feros ve ark., 2013). Kalan çalışmalara bakıldığında ise, kalın bağırsak kanseri (kolorektal) (Hawkes ve ark., 2014 ve Lynch ve ark., 2014), nörofibromatozis (NF1) (Martin ve ark., 2016), beyin tümörü (Kangas ve ark., 2015), yumurtalı (ovarian) kanseri (Rost ve ark., 2012) üzerinde araştırmalar yapıldığı görülmektedir. Bir araştırmada katılımcıların hangi kanser türünde tanı aldıkları bilgisi paylaşılmamıştır (Datta ve ark., 2016).

Bu kapsamda incelenen çalışmalar aracılığıyla farklı türlerde kanser tanısı olan toplam 1200 kişiye ulaşılmış ve ACT temelli çeşitli müdahale programları uygulanmıştır. Katılımcıların yaklaşık üçte ikisinin kadın $(N=745 ; \% 62)$ ve yaşları 18-75 $($ Ort. $=49.8)$ arasında değişen yetişkin katılımcılar olduğu gözlenmektedir. Sadece bir çalışmada 12$21($ Ort. $=16.9, S S=2.9)$ yaş aralığındaki genç yetişkin bireylere yer verilmiştir (Martin ve ark., 2016).

\section{Çalışmaların Amaçları}

Değerlendirilen çalışmalar her ne kadar farklı amaçlara hizmet etse de bazı ortak konular etrafında toplandıkları görülmektedir. Psikolojik esnekliğin/kabulün arttırılması (Arch ve Mitchell, 2016; Hawkes ve ark., 2014; Martin ve ark., 2016; Najvani ve ark., 2015) stresin ve olumsuz duyguların azaltılması (Datta ve ark., 2016; Feros ve ark., 2013; Gonzalez-Fernandez ve ark., 2018; Hawkes ve ark., 2014; Montesinos ve Luciano, 2016), iyilik halinin ve yaşam kalitesinin arttırılması (Datta ve ark., 2016; Feros ve ark., 2013; Hawkes ve ark., 2014; Kangas ve ark., 2015; Rost ve ark., 2012), depresyon ve kaygı düzeylerinin düşürülmesi (Kangas ve ark., 2015; Martin ve ark., 2016; Mohabbat-Bahar ve ark., 2015; Najvani ve ark., 2015; Rost ve ark., 2012), ACT'nin tedaviye uygunluğunun ve etkinliğinin test edilmesi (Datta ve ark., 2016; Lynch ve ark., 2014; Martin ve ark., 2016; Montesinos ve Luciano, 2016; Mosher ve ark., 2018), hastalığın nüksetme (tekrarlama) kaygısının azaltılması (Arch ve Mitchell, 2016; Montesinos ve Luciano, 2016) hedeflenmişsir. Bunların yanı sıra yaşam beklentisinin (Ghasemi ve ark., 
2016) ve travma sonrası gelişim düzeyinin (Hawkes ve ark., 2014) arttırılması, ağrı belirtisi ve yaygınlığının (Martin ve ark., 2016; Mosher ve ark., 2018), tükenmişlik düzeyinin ve uyku sorunlarının (Mosher ve ark., 2018) azaltılması ve davranışsal aktivasyon (Lynch ve ark., 2014) gibi belirtilerin ele alınması hedeflenmiştir.

\section{Tedavi/ Müdahale Yöntemleri ve Süresi}

Her ne kadar bazı çalışmalar içerik, süre ve yöntem açısından birbirinden farklı olsa da bütün araştırmalarda ACT odaklı müdahalelerin uygulandığı görülmektedir. İki araştırmada uygulanan protokolün kaynağına yönelik bilgi verilmezken araştırmaların büyük çoğunluğunda Hayes ve çalışma arkadaşları (Hayes, 2004; Hayes ve ark., 2006; Hayes ve ark., 1999, 2011, 2014) tarafından farklı dönemlerde yayınlanan ACT tedavi içerikleri temel alınmıştır. Araştırmaların yedisinde (\%47) grup temelli tedavi uygulanmış ve telefon destekli uygulanan üç araştırma (\%20) dışındaki beş çalışmada (\%33) yüz yüze tedavi yönteminden yararlanılmıştır (Bkz. Tablo 1).

Tedaviler seans sayıları ve içerik açısından değerlendirildiğinde bütün çalışmalar için seans sayıları 1-12 arasında değişmekle birlikte ortalama seans sayısı 7.9 ve ortalama süre 85 dakika şeklindedir. Üç araştırmanın diğerlerine nazaran seans sayısı olarak daha kısa süreli uygulamalar oldukları görülmektedir (1-4 seans; Ort. $=2.7$ seans, 75 dk.). Bunlardan ilki olan Montesinos ve Luciano'nun (2016) çalışmasında meme kanseri hastalarında hastalığın tekrarlama korkusunu azaltmak amacıyla tek seanslık kısaltılmış bir ACT uygulaması gerçekleştirilmiştir. Müdahale kısmı değerlerin netleştirilmesi, kabul ve ayrışma bileşenlerinden oluşmaktadır. NF1 hastalarıyla yürütülen bir diğer kısa süreli çalışmada (Martin ve ark., 2016) üç seanstan oluşan ACT temelli hasta ve ebeveyn odaklı atölye çalışması gerçekleştirilmiştir. Temelde hastaların ağrılarıyla daha iyi başa çıkmalarını sağlamak hedeflenmiştir. Tedavi planı ergenlere uygun olacak şekilde düzenlenmiş ve farkındalık (mindfulness) temelli teknikler, değerlerle tutarlı hedefler, ayrışma ve kabul teknikleri, uzun ve kısa vadeli hedeflerin belirlenmesi gibi bileşenlerden oluşmaktadır. Ebeveyn kısmında ise çocuklarının değerler doğrultusunda davranışlarını desteklemelerine ve onların ağrılarına yönelik hisleriyle başa çıkmalarına yardımcı olacak uygulamalar gerçekleştirilmiştir. Üçüncü çalışma olan Datta ve arkadaşlarının çalışmasında (2016), Feros ve arkadaşlarının (2013) dört modüllü tedavi protokolünden faydalanılmıştır. Bu modüller, stresli duygu ve düşüncelerin farkındalığ1, farkındalık temelli teknikler, bağlamsal benlik (stresli duygu ve düşüncelerden farklı bir benlik algısı) ve değerlerin belirlenmesi ve onlara yönelik davranışlardan oluşmaktadır. 
Kalan diğer araştırmalarda tedavi süreleri ACT'nin altı temel bileşeni olan anda olmak, değerler, kabul, ayrışma, bağlamsal benlik, değerler doğrultusunda davranışları kapsayıcı şekilde 6-12 seans (Ort. = 9.2 seans, 88 dk.) arasında değişen uygulamalardan oluşmaktadır.

\section{ACT'nin Farklı Sonuç Değişkenleri Üzerindeki Etkileri}

Genel olarak, ACT'nin farklı kanser hastalarının çeşitli belirtileri, duygusal sorunları ve psikolojik esneklik ve kabul düzeyleri üzerindeki etkinliğinin hem bireysel hem de grup müdahaleleri ile test edildiği araştırmaların sonuçları farklı başlıklar altında detaylı olarak incelenmiştir.

Psikolojik esneklik ve kabul. Psikolojik esneklik kavramı ACT uygulamalarının temel hedefidir. Daha önce de belirtildiği gibi kanserle ilgili çalışmalarda bu konu önemlidir. Psikolojik esnekliğin yanı sıra hastalıkla ilgili duygu, düşünceler ve belirtilerin kabulü incelenen çalışmaların önemli bir kısmında öncelikli olarak değerlendirilmiştir. Ancak belirtmek gerekir ki bazı araştırmalarda psikolojik esneklik kavramı yerine kabul ya da yaşantısal kaçınma gibi terimlerin kullanıldığı görülmüştür (Kangas ve ark., 2015). Psikolojik esneklik kavramının öz bildirime dayalı AAQ-II, AAQ-9 (Hayes ve ark., 2004) kullanılarak ölçüldüğü ancak sadece bir çalışmada bir başa çıkma ölçeği olan COPE'un (Carver, Scheier ve Weintraub, 1989) kabul alt ölçeği kullanılarak değerlendirildiği görülmektedir (Rost ve ark., 2012). Düşük puanlar psikolojik esneklikteki artışa işaret etmektedir.

Yalnızca Martin ve arkadaşlarının (2016) çalışmasında hastaların kabul düzeylerinde bir değişim gözlenmezken, psikolojik esneklik düzeyini ölçümleyen toplam dokuz çalışmanın sekizinde (\%89) ön ve son test ölçümlerine göre grup içinde belirlenen alanlarda anlamlı düzeyde artış gözlenmiş ve kazanımların 12 aya kadar devam ettiği aralıklı ölçümlerle gösterilmiştir (Arch ve Mitchell, 2016; Datta ve ark., 2016; Feros ve ark., 2013; Gonzalez-Fernandez ve ark., 2018; Hawkes ve ark., 2014; Kangas ve ark., 2015; Najvani ve ark., 2015; Rost ve ark., 2012). Kontrol grubu kullanan dört çalışmanın tamamında tedavi sonrası müdahale gruplarının psikolojik esneklik düzeyinde kontrol grubuna kıyasla anlamlı azalmalar gözlenmiş ve kazanımlar altı aya kadar sürmüştür (Gonzalez-Fernandez ve ark., 2018; Hawkes ve ark., 2014; Najvani ve ark., 2015; Rost ve ark., 2012). ACT'nin aktif bir tedaviyle karşılaştırmasına baktığımızda AAQ-II puanları bazında davranışsal aktivasyon müdahalesinden (Gonzalez-Fernandez ve ark., 
2018), normal bakımdan (kanseri anlamak, risk faktörlerini azaltmak, beslenme ve fiziksel aktiviteler hakkında bilgilendirici broşürler ve haber bülteni verilmesi) (Hawkes ve ark., 2014) ve COPE puanları bazında normal tedaviden (gevşeme egzersizi, problem çözme ve bilişsel yeniden yapılandırma gibi BDT bileşenleri) (Rost ve ark., 2012) son test ve takip değerlendirmelerinde anlamlı olarak daha etkili olduğu görülmüştür.

Psikolojik belirtiler. Çalışmaların önemli bir kısmında depresyon $(N=9, \% 60)$ ve kaygı $(N=8, \% 53)$ gibi duygusal sorunların yanı sıra hastalıkla ilişkili stresin azaltılmaS1 $(N=4, \% 27)$ önemli hedeflerden biri olarak karşımıza çıkmaktadır. Tablo 1'de görüldüğü üzere üç araştırma dışındaki diğer çalışmalarda, öz bildirime dayalı ve farklı araçlarla ölçülen bu belirtiler açısından ACT uygulamaları sonrasında müdahale grubu son test ölçümlerinde hem ön test ölçümlerine kıyasla hem de kontrol grubu ölçümlerine kıyasla anlamlı düzeyde azalmalar gözlenmiştir (Datta ve ark., 2016; Martin ve ark., 2016; Montesinos ve Luciano, 2016).

Depresyonu değerlendiren çalışmaların sekizinde (\%89) ACT tedavisi sonrasında hastaların depresyon belirtileri anlamlı düzeyde azalmış ve kazanımlar üç aya kadar devam etmiştir (Arch ve Mitchell, 2016; Feros ve ark., 2013; Gonzalez-Fernandez ve ark., 2018; Kangas ve ark., 2015; Mohabbat-Bahar ve ark., 2015; Montazer ve ark., 2017; Najvani ve ark., 2015; Rost ve ark., 2012). Yanı sıra kontrol grubu kullanan beş araştırmanın dördünde $(\% 80)$ ise depresyon düzeyleri açısından müdahale grubunda kontrol grubuna kıyasla anlamlı düzeyde azalma gözlenmiştir (Gonzalez-Fernandez ve ark., 2018; Mohabbat-Bahar ve ark., 2015; Najvani ve ark., 2015; Rost ve ark., 2012). Elde edilen kazanımlar tedavi sonrası üç aya kadar olan ölçümlerde sürmüştür. Hastaların kaygı düzeylerini değerlendiren sekiz çalışmanın yedisinde (\%88) müdahale sonrası hastaların kaygı düzeylerinde anlamlı azalmalar gözlenirken, kazanımlar üç aylık takip ölçümlerinde sürmüştür (Arch ve Mitchell, 2016; Feros ve ark., 2013; Gonzalez-Fernandez ve ark., 2018; Kangas ve ark., 2015; Mohabbat-Bahar ve ark., 2015; Montazer ve ark., 2017; Rost ve ark., 2012). Kontrol grubu karşılaştırmalarında ise beş çalışmanın üçünde (\%60) müdahale grubundaki hastaların kaygı düzeyleri kontrol grubundakilere kıyasla anlamlı şekilde azalmıştır (Gonzalez-Fernandez ve ark., 2018; Mohabbat-Bahar ve ark., 2015; Rost ve ark., 2012). Elde edilen kazanımlar üç aya kadar olan takip ölçümlerinde devam etmiştir. Stres faktörü için bakıldığında ölçüm yapılan çalışmaların tamamında $(N=4)$ hastaların stres düzeylerinde uygulama sonrası anlamlı azalmalar gözlenirken kazanımlar 12 aya kadar sürmüştür (Datta ve ark., 2016; Feros ve ark., 
2013; Hawkes ve ark., 2014; Rost ve ark., 2012). Ancak kontrol grubu olan iki çalışmanın sadece bir tanesinde gruplar arası farklar anlamlı bulunmuştur (Rost ve ark., 2012). Bu kazanımlar ise 3 aya kadar sürmüştür. Öte yandan, Datta ve arkadaşlarının (2016) çalışmasında algılanan stres, Martin ve arkadaşlarının (2016) çalı̧̧masında ise kaygı ve depresyon düzeylerinde müdahale sonrası anlamlı farklar elde edilememiştir. Ayrıca, Montesinos ve Luciano'nun (2016) çalışmasında ACT grubunda kaygı, depresyon ve kaygılı meşguliyet düzeylerinde anlamlı azalmalar gözlenmiş ancak bekleme listesi kontrol grubunda (aktif tedavi grubundan sonra tedavi alacak grup) anlamlı farklar elde edilememiştir. Ek olarak kansere yönelik endişeli davranışlarda (hipokondriyak davranışlarda) hem ACT grubunda hem de bekleme listesi kontrol grubunda anlamlı bir fark gözlenmemiştir.

Yaşam kalitesi ve ilişkili değişkenler. Yaşam beklentisi, kalitesi, yaşamı anlama, kavrama ve yönetebilirlik ve yanı sıra umut düzeyi gibi değişkenler, derleme kapsamında değerlendirdiğimiz çalışmaların sekizi tarafından kanser tanısı olan kişilerde incelenen diğer önemli konular olarak karşımıza çıkmaktadır. ACT tedavisi sonrası ön ve son test farklarına bakan sekiz çalışmanın tamamında hastaların yaşam kalitesi ve ilişkili değişkenler açısından anlamlı ilerlemeler gözlenmiştir (Arch ve Mitchell, 2016; Datta ve ark., 2016; Feros ve ark., 2013; Ghasemi ve ark., 2016; Hawkes ve ark., 2014; Kangas ve ark., 2015; Montazer ve ark., 2017; Rost ve ark., 2012). Ayrıca, takip değerlendirmelerinde kazanımların 12 aya kadar sürdüğü kaydedilmiştir (Hawkes ve ark., 2014). Sadece bir çalışmada ACT müdahalesi sonrasında hastaların yaşam kalitesi düzeylerinde ön ve son test (iki ay sonra) karşılaştırmalarında anlamlı ilerlemeler kaydedilmemiştir (Datta ve ark., 2016). Ancak aynı çalışmada sadece yaşamın anlamı düzeyinde son test ölçümünde ön teste göre anlamlı ilerleme görülmüştür. Grup farkları bakımından ise tedavi olmayan (Ghasemi ve ark., 2016 ve Montazer ve ark., 2017) ve normal tedavi (Rost ve ark., 2012) kontrol grubu kullanan üç çalışmada gruplar arası farkların son test ve altı aya kadar olan takip çalışmalarında anlamlı olduğu bulunmuştur. Yalnızca Hawkes ve arkadaşlarının (2014) çalışmasında normal bakım kontrol grubu ile müdahale grubu arasında yaşam kalitesi düzeyi açısından fark gözlenmemiştir.

Kanserin nüksetme korkusu. Kanser tanısı olan hastalarda yaşanan hastalığın tekrarlayacağına yönelik endişelerin ve korkuların azaltılması iki çalışmanın temel hedeflerinden biri olarak karşımıza çıkmaktadır. Arch ve Mitchell (2016) tarafından gerçekleştirilen ACT temelli grup müdahalesi sonrasında hastalığın tekrarlama korkusunda 
tedavi öncesine göre son test ölçümlerde ve üç aylık takip değerlendirmesinde anlamlı azalmalar kaydedilmiştir. Tek seanslık bireysel müdahalenin uygulandığı diğer çalışmada ise hastalığgin tekrar ortaya çıkma korkusunun yoğunluğu ve yaygınlığında müdahale sonrasında öncesine göre ve üç aylık takipte bekleme listesi kontrol grubuna göre anlamlı azalmalar gözlenmiştir (Montesinos ve Luciano, 2016).

Diğer belirtiler ve kazanımlar. Belirli başlıklar altında toparlanan ortak hedeflerin yanı sıra çalışmalar detaylı olarak incelendiğinde farkındalığın arttırılması, hastalığın sebep olduğu ağrı, tükenmişlik, uyku sorunları ve hareketsiz yaşam tarzının (örn., TV izleme gibi) azaltılması ve travma sonrası gelişimin değerlendirilmesi gibi durumlar da tedavi hedefleri arasındadır.

Bireysel olarak gerçekleştirilen ACT müdahalesi sonrasında hastaların maneviyat (spirituality) ve travma sonrası gelişim düzeylerinde hem tedavi öncesine göre hem de normal bakıma kıyasla anlamlı ilerlemeler kaydedilmiştir (Hawkes ve ark., 2014). Aynı çalışmada tedavi sonrası ACT grubundaki hastaların farkındalık düzeylerinde ilerlemeler gözlenmiş, ancak normal bakım grubuna kıyasla fark anlamlı bulunmamıştır. Müdahale grubundaki kazanımlar altı ve 12 aylık takip değerlendirmesinde devam etmiş, ancak normal bakım grubuyla arasındaki fark sadece travma sonrası gelişim için 12 aya kadar devam etmiştir. Bu sonuçlara ek olarak, uygulanan ACT müdahalesi kanser hastalığının neden olduğu ağrı ve ilişkili diğer belirtileri, tükenmişliği ve uyku sorunlarını tedavi öncesine göre azaltmada ve kazanımların üç aya kadar sürmesinde etkili olmuştur (Martin ve ark., 2016; Mosher ve ark., 2018). Ayrıca, duygusal kontrol ve düşünceleri bastırma davranışlarının hem tedavi öncesine hem de normal tedaviye kıyasla anlamlı olarak azaldığı ve kazanımların üç aya kadar olan takip değerlendirmelerinde devam ettiği görülmüştür (Rost ve ark., 2012). Son olarak, hareketsiz yaşam tarzının tedavi öncesine göre anlamlı düzeyde azaldığı ancak normal bakımdan farklılaşmadığı ve elde edilen kazanımların 12 aya kadar olan takip değerlendirmelerinde devam ettiği kaydedilmiştir (Lynch ve ark., 2014).

\section{TARTIŞMA}

Derleme kapsamında farklı türde kanser tanısı olan hastaların yaşadıkları psikolojik belirtilerin hafifletilmesi amacıyla gerçekleştirilen ACT temelli müdahale çalışmalarına yönelik sistematik bir alan derlemesi gerçekleştirilmiştir. Ulusal ve uluslararası alan taraması sonrası değerlendirme kriterlerini karşılayan 15 çalışmada başta meme kanseri 
olmak üzere diğer kanser türlerinde tanısı olan hastalara yönelik farklı süre, içerik ve yöntemlerde, grup, bireysel ve telefon bazında ACT temelli müdahalelerin uygulandığı görülmektedir.

Çalışmaların önemli bir kısmında hedeflere ulaşıldığı Tablo 1'de net bir şekilde görülmektedir. Uygulanan ACT müdahaleleri sonrasında bulgular bölümünde verilen bilgilerden hareketle, müdahale öncesine göre oransal olarak en yüksek kazanımlar sırasıyla yaşam kalitesi ve ilişkili değişkenlerde (yaşam beklentisi, yaşamı anlama, kavrama, yönetme ve umut düzeyi), stres, nüks endişesi, psikolojik esneklik, depresyon ve kayg1 düzeylerinde gözlenmiştir. Müdahale gruplarında ise psikolojik esneklik, nüks endişesi, depresyon, yaşam kalitesi ve ilişkili değişkenler, kaygı ve stres düzeyleri açısından kontrol gruplarına kıyasla anlamlı ilerlemeler kaydedilmiştir. Bu sıralama, eldeki çalışmalar ve değerlendirmeler neticesinde ACT temelli müdahalelerin kanser hastaları üzerinde en çok etkili olabileceği alanları açık bir şekilde göstermektedir. Bu faktörlere ek olarak, çalışmalarda hem tedavi öncesine hem de kontrol gruplarına kıyasla travma sonrası gelişim ve maneviyat düzeyinde artışlar, duygusal kontrol ve düşünceleri bastırma davranışlarında azalmalar gözlenmiştir. Tedavi öncesine kıyasla hastaların farkındalık düzeyinde artışın yanı sıra ağrı ve ilişkili belirtiler, tükenmişlik, uyku sorunları ve hareketsiz yaşam tarzında anlamlı azalmalar görülmüsştür. Müdahaleler sonrasında elde edilen bütün kazanımlar tedavi öncesine göre ortalama olarak 4.1 ay, kontrol gruplarına kıyasla ortalama 5 ay süresince devam etmiştir.

Tedavi kazanımları 1-12 seanslık (Ort. $=7.9,85 \mathrm{dk}$.) ACT müdahaleleri sonucunda gerçekleşmiştir. Her ne kadar toplam seans sayıları arasında önemli farklılıklar olsa da, ACT uygulamalarının en dikkat çekici özelliklerinden birisi olarak daha kısa süreli uygulamalarda dahi tedavi öncesine ve kontrol gruplarına kıyasla anlamlı düzeyde kazanımlara yol açması gösterilebilir. Montesinos ve Luciano'nun (2016) çalışmasında olduğu gibi bir seanslık bireysel uygulamalarda dahi kontrol grubuna kıyasla anlamlı ve etkili ilerlemeler elde edilebilmektedir. Bu yönüyle ACT, yaşam motivasyonlarını kaybetmekte ya da kaybetmiş ve tedavi açısından zamanı sınırlı olan kanser gibi bir hasta grubunda etkili ve alternatif bir tedavi ihtiyacını karşılayabilir. Ayrıca bulgular göstermektedir ki yaşam kalitesi ve ilişkili değişkenler açısından ACT müdahaleleri etkili sonuçlar ortaya koymaktadır. Yakın bir süre önce bu çalışma ile benzer şekilde farklı türde kanser tanısı olan hastalara uygulanan ACT ile ilgili bir derleme çalışması gerçekleştirilmiştir. Bulgular, ACT uygulamaları sonrasında kanser hastalarının yaşam kaliteleri ve 
psikolojik esneklik belirtilerinin iyileşmesinin yanı sıra stres, duygusal rahatsızlıklar, fiziksel acı ve travmatik tepkilerde azalmalar olduğunu göstermiştir (Fashler ve ark., 2018).

Çalışmalar yöntemsel açıdan değerlendirildiğinde tamamında ön ve son test araştırma desenleri kullanılmış ancak, sadece dört çalışmanın randomize kontrollü olarak gerçekleştirildiği görülmüştür. Buna ek olarak dört çalışmada tedavi olmayan kontrol grubunun kullanıldığı (kontrol grubundaki katılımcıların hiç tedavi almadığı), sadece bir çalışmada bekleme listesi kontrol grubunun yer aldığı görülmektedir. Beş araştırmada ise herhangi bir kontrol grubuna yer verilmemiştir. Randomize kontrollü çalışmanın d1şında sadece Rost ve arkadaşlarının (2012) çalışmasında bilişsel davranışçı bileşenlerden meydana gelen aktif bir tedavi kontrol grubu yer almaktadır. Bütün çalışmalarda ön test ve son test ölçümlerin yer alıyor olması sonuçlara duyulan güveni arttırmaktadır. Ancak yine de, özellikle kontrol grubunun yer almadığı ön test ve son test ölçümlerini kullanan çalışmalarda etkinin tedaviden mi, yoksa zamanla kendiliğinden bir gelişim ya da ortalamaya gerileme gibi diğer nedenlerden mi kaynaklandığını kestirmek zor olmaktadır (Cuijpers, Weitz, Cristea ve Twisk, 2017). Bu nedenle günümüzde randomize kontrollü çalışmalar, alan yazında bazı eleştiriler alıyor olsa da nedensel ilişkilerin açıklanmasında araştırma tasarımı olarak altın standarttır (Backmann, 2017).

Randomize kontrollü çalışmaların tasarım, uygulama, analiz ve raporlama süreçlerindeki kusurların, uygulanan müdahalenin etkisinin hafife alınmasına ya da abartılmasına yol açabileceği ileri sürülmekte ve bu nedenle Cochrane Collaboration tarafından ‘yanlılık riski ölçüm aracı' (tool for assessing risk of bias) (Higgins ve ark., 2011) ve CONSORT tarafından 'akış şeması' ve 'kontrol listesi' (Schulz, Altman ve Moher, 2010) gibi araçlar önerilmektedir. Ancak, derlemedeki randomize çalışmalardan sadece birinde CONSORT akış şemasının kullanıldığı ve yanı sıra tedaviye bağlılık (fidelity) değerlendirmesinin raporlandığg görülmektedir (Mosher ve ark., 2018).

Araştırmalara örneklem özellikleri açısından bakıldığında kadınların erkeklerden daha fazla olduğu $(\% 62)$ ve ağırlıklı olarak yetişkin bireylerden $($ Ort. $=49.8)$ oluştuğu görülmektedir. Sadece bir çalışmada 12-21 yaş aralığındaki ergen ve genç yetişkin bireyler yer almıştır (Martin ve ark., 2016). Çalışmaların yedisinde (\%47) meme kanseri hastalarına yer verilmiştir. Bu durumun kanserle ilgili çalışmalarda yaygın olması ve yanı sıra kanser ya da kronik hastalıkların ileri yaşlarda daha çok gözlenen durumlar 
olması, katılımcıların cinsiyet ve yaş dağılımlarının normal olduğu düşündürmektedir. Bu nedenle, ACT tedavilerinden elde edilen bu kazanımların kanser hastaları için önemli ölçüde geçerli ve genellenebilir bulgular olduğu söylenebilir.

Çalışmaların yöntemsel sınırlılıklarının ötesinde bu derlemenin kendisiyle de ilgili bazı kısıtlılıklar bulunmaktadır. Örneğin çalışmaya sadece Türkçe ve İngilizce dillerinde yayınlanmış araştırmalar dahil edilmiştir. Daha farklı diller ya da kültürlerdeki çalışmalar ACT uygulamalarının sonuçlarının genellenebilirliğine yönelik bilgiler sunabilir. Yanı sıra APA PsycNET gibi alandaki önemli bir veri tabanına erişimin olmamasından dolayı buradaki kaynaklar taranamamıştır. Ek olarak, tedaviden elde edilen sonuçların karşılaştırmaları istatistiki anlamlılık üzerinden yürütülmüştür. Anlamlılı̆̆ın yanı sıra etki boyutuna yönelik karşılaştırmalar ve meta-analiz çalışmaları yukarıda sıralanan kazanımlara yönelik daha net bilgiler sunacaktır.

Sonuç olarak, ACT temelli müdahale yöntemleri yeni uygulanmakta olan bir tedavi yaklaşımı olarak, farklı türlerdeki kanser tanısı olan bireylerin psikolojik problemlerinin azaltılmasında etkili ve alternatif bir tedavi yöntemi olarak kendini göstermektedir. Çalışmalar her ne kadar olumlu sonuçlara işaret etse de, araştırma desenleri açısından sahip oldukları sınırlılıklar sonuçların net bir şekilde yorumlanmasını güçleştirmektedir. $\mathrm{Bu}$ nedenle, aktif kontrol grubunun ya da en azından bekleme listesi ve tedavi olmayan kontrol grubu gibi grup karşılaştırmalarının yapılabileceği, örneklem seçiminde ve tedavi sürecinde randomizasyonun sağlandığı çalışmalara ihtiyaç duyulmaktadır. Yanı sıra, elde edilen kazanımların daha uzun süreli takip edildiği çalışmalar ilgili kazanımların kalıcılığına yönelik daha net bilgiler sunacaktır.

Finansal Destek: Yazar bu çalışma için finansal destek almamıştır.

\section{Kaynakça}

Arch, J. J. ve Mitchell, J. L. (2016). An Acceptance and Commitment Therapy (ACT) group intervention for cancer survivors experiencing anxiety at re-entry. Psycho-Oncology, 25(5), 610-615. https:// doi.org/10.1002/pon.3890.

Bach, P., Hayes, S. C. ve Gallop, R. (2012). Long term effects of brief Acceptance and Commitment Therapy for psychosis. Behavior Modification, 36, 165-181.

Backmann, M. (2017). What's in a gold standard? In defence of randomised controlled trials. Medicine, Health Care and Philosophy, 20(4), 513-523.

Bluett, E. J., Homan, K. J., Morrison, K. L., Levin, M. E. ve Twohig, M. P. (2014). Acceptance and commitment therapy for anxiety and OCD spectrum disorders: An empirical review. Journal of Anxiety Disorders, 28(6), 612-624. https://doi.org/10.1016/j.janxdis.2014.06.008. 
Bond, F. W., Hayes, S. C., Baer, R. A., Carpenter, K. M., Guenole, N., Orcutt, H. K., ... ve Zettle, R. D. (2011). Preliminary psychometric properties of the Acceptance and Action Questionnaire-II: A revised measure of psychological inflexibility and experiential avoidance. Behavior Therapy, 42(4), 676-688.

Buki, L. P., Reich, M. ve Lehardy, E. N. (2016). "Our organs have a purpose": body image acceptance in Latina breast cancer survivors. Psycho-Oncology, 25(11), 1337-1342.

Carver, C. S., Scheier, M. F. ve Weintraub, K. J. (1989). Assessing coping strategies: A theoretically sased approach. Journal of Personality and Social Psychology. https://doi.org/10.1037/00223514.56.2.267.

Chen, S., Liu, J., Zhang, Z. ve Li, Z. (2017). Self-acceptance and associated factors among Chinese women with breast cancer. Journal of Clinical Nursing, 26(11-12), 1516-1523.

Cuijpers, P., Weitz, E., Cristea, I. A. ve Twisk, J. (2017). Pre-post effect sizes should be avoided in meta-analyses. Epidemiology and Psychiatric Sciences, 26(4), 364-368.

Datta, A., Aditya, C., Chakraborty, A., Das, P. ve Mukhopadhyay, A. (2016). The potential utility of Acceptance and Commitment Therapy (ACT) for reducing stress and improving wellbeing in cancer patients in Kolkata. Journal of Cancer Education, 31(4), 721-729. https://doi.org/10.1007/ s13187-015-0935-8.

De la Torre-Luque, A., Gambara, H., López, E. ve Cruzado, J. A. (2015). Psychological treatments to improve quality of life in cancer contexts: A meta-analysis. International Journal of Clinical and Health Psychology, 16(2), 211-219. https://doi.org/10.1016/j.ijchp.2015.07.005.

Dunne, S., Mooney, O., Coffey, L., Sharp, L., Timmons, A., Desmond, D., ... ve Gallagher, P. (2017). Self-management strategies used by head and neck cancer survivors following completion of primary treatment: A directed content analysis. Psycho-Oncology, 26(12), 1-7. https://doi. org/10.1002/pon.4447.

Faraji, J., Mahdavi, A., Samkhaniyan, E., Asadi, S. H. ve Dezhkam, N. (2015). A review of the effectiveness of cognitive-behavioral group therapy on the reduction of body image concern in patients with breast cancer. Journal of Medicine and Life, 8(4), 82-86.

Fashler, S. R., Weinrib, A. Z., Azam, M. A. ve Katz, J. (2018). The use of Acceptance and Commitment Therapy in oncology settings: A narrative review. Psychological Reports, 121(2), 229-252.

Feros, D. L., Lane, L., Ciarrochi, J. ve Blackledge, J. T. (2013). Acceptance and Commitment Therapy (ACT) for improving the lives of cancer patients: a preliminary study. Psycho-Oncology, 22(2), 459-464. https://doi.org/10.1002/pon.2083.

Forman, E. M., Shaw, J. A., Goetter, E. M., Herbert, J. D., Park, J. A. ve Yuen, E. K. (2012). Longterm follow-up of a randomized controlled trial comparing Acceptance and Commitment Therapy and Standard Cognitive Behavior Therapy for anxiety and depression. Behavior Therapy, 43(4), 801-811. https://doi.org/10.1016/j.beth.2012.04.004.

Ghasemi, F., Dehghan, F., Farnia, V., Tatari, F. ve Alikhani, M. (2016). Effectiveness of Acceptance and Commitment Therapy on life expectancy of female cancer patients at Tehran's Dehshpour Institute in 2015. Asian Pacific Journal of Cancer Prevention, 17(8), 4113-4116. Erişim adresi: http://www. ncbi.nlm.nih.gov/pubmed/27644670.

Gonzalez-Fernandez, S., Fernandez-Rodriguez, C., Paz-Caballero, M. D. ve Perez-Alvarez, M. (2018). Treating anxiety and depression of cancer survivors: Behavioral activation versus acceptance and commitment therapy. Psicothema, 30(1), 14-20. https://doi.org/10.7334/psicothema2017.396.

Graham, C. D., Gouick, J., Krahé, C. ve Gillanders, D. (2016). A systematic review of the use of Acceptance and Commitment Therapy (ACT) in chronic disease and long-term conditions. Clinical Psychology Review, 46, 46-58. https://doi.org/10.1016/j.cpr.2016.04.009. 
Gregurek, R., Bras, M., Dordević, V., Ratković, A.S. ve Brajković, L. (2010). Psychological problems of patients with cancer. Psychiatria Danubina, 22(2), 227-30. Erişim adresi: http://www.ncbi.nlm. nih.gov/pubmed/20562751.

Harris, R. (2016). ACT’ı kolay öğrenmek: Illkeler ve ötesi için hızlı bir başlangıç. (Kollektif çev.). İstanbul: Litera Yayıncılık.

Hawkes, A. L., Pakenham, K. I., Chambers, S. K., Patrao, T. A. ve Courneya, K. S. (2014). Effects of a multiple health behavior change intervention for colorectal cancer survivors on psychosocial outcomes and quality of life: A randomized controlled trial. Annals of Behavioral Medicine, 48(3), 359-370. https://doi.org/10.1007/s12160-014-9610-2.

Hawkes, A. L., Pakenham, K. I., Courneya, K. S., Gollschewski, S., Baade, P., Gordon, L. G., ... ve Chambers, S. K. (2009). A randomised controlled trial of a tele-based lifestyle intervention for colorectal cancer survivors ('CanChange'): Study protocol. BMC Cancer, 9(1), 1-8.

Hayes, S. C. (2004). Acceptance and commitment therapy, relational frame therapy, and the third wave of behavioral and cognitive therapies. Behavior Therapy, 35(4), 639-665.

Hayes, S. C., Strosahl, K., Wilson, K. G., Bissett, R. T., Pistorello, J., Toarmino, D., ... Mccurry, S. M. (2004). Measuring experiential avoidance: A preliminary test of a working model. Psychological Record, 54(4), 553-578. https://doi.org/10.1007/BF03395492.

Hayes, S. C., Luoma, J. B., Bond, F. W., Masuda, A. ve Lillis, J. (2006) Acceptance and commitment therapy: Model, processes and outcomes. Behavior Research and Theraphy, 44(1),1-25. https://doi. org/10.1016/j.brat. 2005.06.006.

Hayes, S. C. ve Strosahl, K. D. (2010). A practical guide to acceptance and commitment therapy. New York: Springer.

Hayes, S. C., Strosahl, K. D. ve Wilson, K. G. (1999). Acceptance and commitment therapy: An experiential approach to behaviour change. New York: The Guilford Press.

Hayes, S. C., Strosahl, K. D. ve Wilson, K. G. (2011). Acceptance and Commitment Therapy: The process and practice of mindful change. New York: Guilford.

Hayes, S. C., Strosahl, K. ve Wilson K. G. (2014). Terapia de aceptación y compromiso. Proceso y práctica del cambio consciente (Mindfulness). Bilbao: Desclée de Brouwer.

Heins, M. J., Korevaar, J. C., Rijken, P. M. ve Schellevis, F. G. (2013). For which health problems do cancer survivors visit their General Practitioner? European Journal of Cancer, 49(1), 211-218. https://doi.org/10.1016/j.ejca.2012.07.011.

Higgins, J. P. T., Altman, D. G., Gøtzsche, P. C., Jüni, P., Moher, D., Oxman, A. D., .. Sterne, J. A. C. (2011). The Cochrane Collaboration's tool for assessing risk of bias in randomised trials. BMJ, 343, 1-9. https://doi.org/10.1136/bmj.d5928.

Hulbert-Williams, N. J., Storey, L. ve Wilson, K. G. (2015). Psychological interventions for patients with cancer: Psychological flexibility and the potential utility of Acceptance and Commitment Therapy. European Journal of Cancer Care, 24(1), 15-27.

Johns, S. A., Brown, L. F., Beck-Coon, K., Monahan, P. O., Tong, Y. ve Kroenke, K. (2016). Randomized controlled pilot study of mindfulness-based stress reduction for persistently fatigued cancer survivors. Psycho-Oncology, 24(8), 885-893.

Kamińska, M., Ciszewski, T., Bronikowska, A., Ferańska, M., Pawlak-Warszawska, A. ve Paśnik, E. (2014). Acceptance of the illness and the quality of life of patients with breast cancer. Polish Journal of Public Health, 124(1), 5-9.

Kangas, M. ve McDonald, S. (2011) Is it time to act? The potential of acceptance and commitment therapy for psychological problems following acquired brain injury. Neuropsychological Rehabilitation, 21(2), 250-276. 
Kangas, M., McDonald, S., Williams, J. R. ve Smee, R. I. (2015). Acceptance and commitment therapy program for distressed adults with a primary brain tumor: A case series study. Supportive Care in Cancer, 23(10), 2855-2859. https://doi.org/10.1007/s00520-015-2804-8.

Köhle, N., Drossaert, C. H. C., Jaran, J., Schreurs, K. M. G., Leeuw, I. M. V. ve Bohlmeijer, E. T. (2017). User-experiences with a web-based self-help intervention for partners of cancer patients based on acceptance and commitment therapy and self-compassion: A qualitative study. BMC Public Health, 17(1), 225. https://doi.org/10.1186/s12889-017-4121-2.

Liberati, A., Altman, D. G., Tetzlaff, J., Mulrow, C., Gøtzsche, P. C., Ioannidis, J. P. A., Moher, D. (2009). The PRISMA statement for reporting systematic reviews and meta-analyses of studies that evaluate health care interventions: Explanation and elaboration. PLoS Medicine, 6(7), e1000100.

Linden, W. ve Girgis, A. (2012). Psychological treatment outcomes for cancer patients: What do meta-analyses tell us about distress reduction? Psycho-Oncology, 21(4), 343-350. https://doi.org/10.1002/pon.2035.

Lynch, B. M., Courneya, K. S., Sethi, P., Patrao, T. A. ve Hawkes, A. L. (2014). A Randomized controlled trial of a multiple health behavior change intervention delivered to colorectal cancer survivors. Cancer, 120(17), 2665-2672. https://doi.org/10.1002/cncr.28773.

Martin, S., Wolters, P. L., Toledo-Tamula, M. A., Schmitt, S. N., Baldwin, A., Starosta, A., ... Widemann, B. (2016). Acceptance and Commitment Therapy in youth with neurofibromatosis type 1 (nfl) and chronic pain and their parents: A pilot study of feasibility and preliminary efficacy. American Journal of Medical Genetics Part A, 170(6), 1462-1470. https://doi.org/10.1002/ajmg.a.37623.

Miovic, M. ve Block, S. (2007). Psychiatric disorders in advanced cancer. Cancer, 110(8), 1665-1676. https://doi.org/10.1002/cncr.22980.

Mohabbat-Bahar, S., Maleki-Rizi, F., Akbari, M. E. ve Moradi-Joo, M. (2015). effectiveness of group training based on Acceptance And Commitment Therapy on anxiety and depression of women with breast cancer. Iranian Journal of Cancer Prevention, 8(2), 71-76.

Montazer, A., Nemati, F., Dehghani, F. ve Fallah, T. (2017). Efficacy of Acceptance and Commitment Therapy on breast cancer female patients' hope. Iranian Journal of Cancer Prevention, 10(2). https://doi.org/Artn E552610.5812/Ijcp.5526.

Montesinos, F. ve Luciano, C. (2016). Acceptance of relapse fears in breast cancer patients: Effects of an ACT-based abridged intervention. Psicooncología, 13(1), 7-21.

Mosher, C. E., Secinti, E., Li, R. H., Hirsh, A. T., Bricker, J., Miller, K. D., ... Johns, S. A. (2018). Acceptance and commitment therapy for symptom interference in metastatic breast cancer patients: a pilot randomized trial. Supportive Care in Cancer, 26(6), 1993-2004. https://doi.org/10.1007/s00520-018-4045-0.

Najvani, B. D., Neshatdoost, H. T., Abedi, M. R. ve Mokarian, F. (2015). The effect of acceptance and commitment therapy on depression and psychological flexibility in women with breast cancer. Zahedan Journal of Research in Medical Sciences, 17(4), 2383-2894).

Nenova, M., Morris, L., Paul, L., Li, Y., Applebaum, A. ve DuHamel, K. (2013). Psychosocial interventions with cognitive-behavioral components for the treatment of cancer-related traumatic stress symptoms: A review of randomized controlled trials. Journal of Cognitive Psychotherapy, 27(3), 258-284. https://doi.org/10.1891/0889-8391.27.3.258.

Ogden, J. (2016). HIV ve kanser: hastalık sürecinde psikoloji. G. Dirik (Ed.), Sağllk psikolojisi kitabı içinde (s. 369-390). Ankara: Nobel Akademik Yayıncılık.

Peoples, A. R., Garland, S. N., Perlis, M. L., Savard, J., Heckler, C. E., Kamen, C. S., ... Roscoe, J. A. (2017). Effects of cognitive behavioral therapy for insomnia and armodafinil on quality of life in cancer survivors : a randomized placebo-controlled trial, Journal of Cancer Survivorship, 11(3) 401-409. https://doi.org/10.1007/s11764-017-0597-0. 
Politi, M. C., Enright, T. M. ve Weihs, K. L. (2007). The effects of age and emotional acceptance on distress among breast cancer patients. Supportive Care in Cancer, 15(1), 73-79.

Ream, E., Gargaro, G., Barsevick, A. ve Richardson, A. (2015). Management of cancer-related fatigue during chemotherapy through telephone motivational interviewing: Modeling and randomized exploratory trial. Patient Education and Counseling, 98(2), 199-206. https://doi.org/10.1016/j.pec.2014.10.012.

Rost, A. D., Wilson, K., Buchanan, E., Hildebrandt, M. J. ve Mutch, D. (2012). Improving psychological adjustment among late-stage ovarian cancer patients: Examining the role of avoidance in treatment. Cognitive and Behavioral Practice, 19(4), 508-517. https://doi.org/DOI 10.1016/j. cbpra.2012.01.003.

Schulz, K. F., Altman, D. G. ve Moher, D. (2010). CONSORT 2010 Statement: updated guidelines for reporting parallel group randomised trials. BMC Medicine, 8, 1-9. https://doi.org/10.1136/bmj.c332.

Spencer, J. C. ve Wheeler, S. B. (2016). A systematic review of Motivational Interviewing interventions in cancer patients and survivors. Patient Education and Counseling, 99(7), 1099-1105. https://doi. org/10.1016/j.pec.2016.02.003.

Swain, J., Hancock, K., Hainsworth, C. ve Bowman, J. (2013). Acceptance and Commitment Therapy in the treatment of anxiety: A systematic review. Clinical Psychology Review, 33(8), 965-978. https://doi.org/10.1016/j.cpr.2013.07.002.

Şencan, İ. ve Keskinkılıç, B. (Ed.). (2017). Türkiye kanser istatistikleri. Ankara: Türkiye Halk Sağlı̆̆ Kurumu.

Türkiye İstatistik Kurumu. (2018). Ölüm nedeni istatistikleri, 2017. Erişim adresi: http://www.tuik.gov. tr/PreHaberBultenleri.do?id=27620

Veehof, M. M., Oskam, M. J., Schreurs, K. M. G. ve Bohlmeijer, E. T. (2011). Acceptance-based interventions for the treatment of chronic pain: A systematic review and meta-analysis. Pain, 152(3), 533-542. https://doi.org/10.1016/j.pain.2010.11.002.

Watson, M., White, C., Lynch, A. ve Mohammed, K. (2017). Telephone - delivered individual Cognitive Behavioural Therapy for cancer patients : An equivalence randomised trial. Psycho-Oncology, 26(3), 301-308. https://doi.org/10.1002/pon.4338.

Wootten, A. C., Meyer, D., Abbott, J.-A. M., Chisholm, K., Austin, D. W., Klein, B., ... Costello, A. J. (2016). An online psychological intervention can improve the sexual satisfaction of men following treatment for localized prostate cancer: outcomes of a Randomised Controlled Trial evaluating My Road Ahead. Psycho-Oncology, 26(7), 975-981. https://doi.org/10.1002/pon.4244.

World Health Organisation. (2018). The top 10 causes of death. Erişim adresi: https://www.who.int/ news-room/fact-sheets/detail/the-top-10-causes-of-death

Xiao, F., Song, X., Chen, Q., Dai, Y., Xu, R., Qiu, C. ve Guo, Q. (2016). Effectiveness of psychological interventions on depression in patients after breast cancer surgery: A meta-analysis of randomized controlled trials. Clinical Breast Cancer, 17(3), 171-179. https://doi.org/10.1016/j.clbc.2016.11.003.

Yaman, Ş. ve Ayaz, S. (2016). Psychological problems experienced by women with gynecological cancer and how they cope with it: A phenomenological study in Turkey. Health and Social Work, 41(3), 173-181. https://doi.org/10.1093/hsw/hlw030.

Yastıbaş, C. ve Dirik, G. (2018). Kanser ve farkındalık temelli müdahale programları: sistematik derleme. Psikiyatride Güncel Yaklaşımlar-Current Approaches in Psychiatry, 10(3), 375-393.

Yavuz, K. F. (2015). Kabul ve Kararlı1ık Terapisi (ACT): Genel bir bakış. Türkiye Klinikleri Journal of Psychiatry Special Topics, 8(2), 21-27. 
